NASA/TM-2002-211350

Flowfield Comparisons From Three Navier-Stokes Solvers for an Axisymmetric Separate Flow Jet

L. Danielle Koch and James Bridges

Glenn Research Center, Cleveland, Ohio

Abbas Khavaran

QSS Group, Inc., Cleveland, Ohio 
Since its founding, NASA has been dedicated to the advancement of aeronautics and space science. The NASA Scientific and Technical Information (STI) Program Office plays a key part in helping NASA maintain this important role.

The NASA STI Program Office is operated by Langley Research Center, the Lead Center for NASA's scientific and technical information. The NASA STI Program Office provides access to the NASA STI Database, the largest collection of aeronautical and space science STI in the world. The Program Office is also NASA's institutional mechanism for disseminating the results of its research and development activities. These results are published by NASA in the NASA STI Report Series, which includes the following report types:

- $\quad$ TECHNICAL PUBLICATION. Reports of completed research or a major significant phase of research that present the results of NASA programs and include extensive data or theoretical analysis. Includes compilations of significant scientific and technical data and information deemed to be of continuing reference value. NASA's counterpart of peerreviewed formal professional papers but has less stringent limitations on manuscript length and extent of graphic presentations.

- TECHNICAL MEMORANDUM. Scientific and technical findings that are preliminary or of specialized interest, e.g., quick release reports, working papers, and bibliographies that contain minimal annotation. Does not contain extensive analysis.

- CONTRACTOR REPORT. Scientific and technical findings by NASA-sponsored contractors and grantees.
- CONFERENCE PUBLICATION. Collected papers from scientific and technical conferences, symposia, seminars, or other meetings sponsored or cosponsored by NASA.

- SPECIAL PUBLICATION. Scientific, technical, or historical information from NASA programs, projects, and missions, often concerned with subjects having substantial public interest.

- TECHNICAL TRANSLATION. Englishlanguage translations of foreign scientific and technical material pertinent to NASA's mission.

Specialized services that complement the STI Program Office's diverse offerings include creating custom thesauri, building customized data bases, organizing and publishing research results ... even providing videos.

For more information about the NASA STI Program Office, see the following:

- Access the NASA STI Program Home Page at http://www.sti.nasa.gov

- E-mail your question via the Internet to help@sti.nasa.gov

- Fax your question to the NASA Access Help Desk at 301-621-0134

- Telephone the NASA Access Help Desk at 301-621-0390

- Write to:

NASA Access Help Desk

NASA Center for AeroSpace Information 7121 Standard Drive

Hanover, MD 21076 
NASA/TM-2002-211350

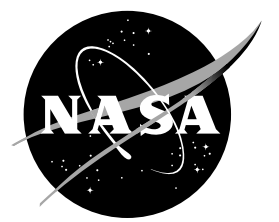

\section{Flowfield Comparisons From Three Navier-Stokes Solvers for an Axisymmetric Separate Flow Jet}

L. Danielle Koch and James Bridges

Glenn Research Center, Cleveland, Ohio

Abbas Khavaran

QSS Group, Inc., Cleveland, Ohio

Prepared for the

40th Aerospace Sciences Meeting and Exhibit

sponsored by the American Institute of Aeronautics and Astronautics

Reno, Nevada, January 14-17, 2002

National Aeronautics and

Space Administration

Glenn Research Center 


\section{Acknowledgments}

The first author would like to extend her thanks to Dennis Yoder and Nicholas Georgiadis for their help in using the WIND code and to Christopher Miller for his comments given in discussion of the overall results and grid study.

Available from

NASA Center for Aerospace Information 7121 Standard Drive

Hanover, MD 21076
National Technical Information Service 5285 Port Royal Road Springfield, VA 22100

Available electronically at http://gltrs.grc.nasa.gov/GLTRS 


\title{
FLOWFIELD COMPARISONS FROM THREE NAVIER-STOKES SOLVERS FOR AN AXISYMMETRIC SEPARATE FLOW JET
}

\author{
L. Danielle Koch* and James Bridges* \\ National Aeronautics and Space Administration \\ Glenn Research Center \\ Cleveland, Ohio 44135 \\ Abbas Khavaran* \\ QSS Group, Inc. \\ Cleveland, Ohio 44135
}

\begin{abstract}
$\underline{\text { Abstract }}$
To meet new noise reduction goals, many concepts to enhance mixing in the exhaust jets of turbofan engines are being studied. Accurate steady state flowfield predictions from state-of-the-art computational fluid dynamics (CFD) solvers are needed as input to the latest noise prediction codes. The main intent of this paper was to ascertain that similar NavierStokes solvers run at different sites would yield comparable results for an axisymmetric two-stream nozzle case. Predictions from the WIND and the NPARC codes are compared to previously reported experimental data and results from the CRAFT NavierStokes solver. Similar k-epsilon turbulence models were employed in each solver, and identical computational grids were used. Agreement between experimental data and predictions from each code was generally good for mean values. All three codes underpredict the maximum value of turbulent kinetic energy. The predicted locations of the maximum turbulent kinetic energy were farther downstream than seen in the data. A grid study was conducted using the WIND code, and comments about convergence criteria and grid requirements for CFD solutions to be used as input for noise prediction computations are given. Additionally, noise predictions from the MGBK code, using the CFD results from the CRAFT code, NPARC, and WIND as input are compared to data.
\end{abstract}

\section{$\underline{\text { Introduction }}$}

In 1994, NASA Glenn Research Center initiated work to reduce noise from the exhaust jets of turbofan engines under the Advanced Subsonic Transport (AST) program. An experimental program was designed to quantify jet noise reductions achieved by the addition of passive mixing devices (tabs and chevrons) to the core nozzle of a separate-flow jet. The baseline nozzle model that had no tabs or chevrons is shown in Figure 1 (3BB). Researchers seek to understand more clearly how these passive mixing devices act to reduce noise, and look to results from current Navier-Stokes solvers and acoustic codes to shed light on the complex physics of these jets.

The goal of this paper was to address three issues related to mean flow and acoustic predictions for the baseline nozzle shown in Figure 1. First, we wanted to determine if three different Navier-Stokes codes run at three separate locations using the same computational grid and input conditions would yield similar results. Secondly, since the output from the Navier-Stokes codes would be used as input to the MGBK acoustic code, efforts were made to determine what would be suitable convergence criteria for the mean flow solutions. Lastly, a grid study was conducted to determine if the initial grid would yield grid independent acoustic results.

\section{$\underline{\text { Aerodynamic Predictions }}$}

\section{Computational Details}

The CRAFT code, developed by Combustion Research and Flow Technology, Inc. is a finite-volume structured Navier-Stokes code. The WIND code was developed by the NPARC Alliance and the Boeing Company and is also a structured, multi-zoned compressible flow solver. NPARC was developed by the NPARC Alliance members, NASA Glenn Research

*Senior Member, AIAA. 
Center and the U.S. Air Force Arnold Engineering Development Center. It is also a general purpose code that solves the Navier-Stokes equations in a centraldifference form. The experimental data for this axisymmetric jet case, as well as for nozzles employing tabs and chevrons were collected at the NASA Glenn Research Center. More details about the CRAFT Navier-Stokes solver and the experimental data are given in Reference 1. The WIND and NPARC codes are described more fully in Reference 2.

Several key features were common between the three different Navier-Stokes solvers used in this study. Each was capable of running multiple-block structured grids with I-blanked sections. Each had a selection of turbulence models, and each allowed the user to specify the turbulent Prandtl number. Each code was capable of running 2-dimensional or 3-dimensional problems. Every attempt was made to formulate the input for each simulation to be as identical as possible. Based on the recommendations of Kenzakowski, et al. in Reference 1, the Chien k-epsilon turbulence model was used for each simulation with a turbulent Prandtl number of 0.70 . No compressibility corrections were used in the simulations.

The computational grid for the two-stream separate flow jet, mirrored about the $\mathrm{x}$ axis, is shown in Figures 2 and 3 (gridlines have been removed in both views for clarity). This grid was originally generated by Kenzakowski, et al. and was also used in the WIND and NPARC simulations. Portions of the core and fan duct are represented in the single-block I-blanked, 2-dimensional grid. The grid had 547 gridlines in the axial direction, and 160 gridlines in the radial direction. The grid extended at least 15 fan diameters downstream of the centerbody trailing edge. The grid was relatively loosely packed near the solid surfaces to minimize computational costs. Because of this, wall functions were employed in each code to calculate the near wall flow characteristics. Uniform subsonic conditions were imposed at all inflow boundaries and are given in the table below.

\begin{tabular}{|l|c|}
\hline \multicolumn{2}{|c|}{ Fan Conditions } \\
\hline Total Pressure & $26.353 \mathrm{psia}$ \\
\hline Total Temperature & $600.000 \mathrm{R}$ \\
\hline \multicolumn{2}{|c|}{ Core Conditions } \\
\hline Total Pressure Freestream Conditions \\
\hline Total Temperature & $24.193 \mathrm{psia}$ \\
\hline \multicolumn{2}{|c|}{ Fo0.000 R } \\
\hline Static Pressure & $14.400 \mathrm{psia}$ \\
\hline Static Temperature & $529.670 \mathrm{R}$ \\
\hline Mach Number & 0.28 \\
\hline
\end{tabular}

Careful consideration was given to the criteria chosen to monitor convergence of the new aerodynamic predictions from the WIND and NPARC codes. Georgiadis, et al. established two criteria for determining the final solution for a single stream jet in Reference 2. In the two-dimensional ejector nozzle described in Reference 2, the L2 residual error was required to drop at least four orders of magnitude, and the changes in the velocity at all points along the centerline were monitored from one iteration set to the next (500-1000 iterations per set). They considered a "final solution" to have been reached when the changes in centerline velocities from set to set were below 0.001 percent.

The convergence criteria established by Georgiadis, et al. was adapted to the more complicated separate flow nozzle studied in this work. Here, calculations were run in sets of 5000 iterations each. L2 residual errors were required to drop by at least three orders of magnitude. Adjusting for the larger number of iterations per set, a "final solution based on centerline velocities" was reached when changes in centerline velocities from set to set were no more than 0.01 percent.

Since these steady state aerodynamic predictions were going to be used as input for an acoustic prediction code, an additional convergence criterion was added. As reported by Hamed, et al. in Reference 3 , acoustic predictions are sensitive to the maximum level of turbulent kinetic energy and the dissipation rate. For a single stream jet, the maximum level of turbulent kinetic energy would lie along a lip line originating from the nozzle exit. Since the two-stream nozzle studied here had no such obvious lip line, an "equivalent lip line" was established for the purpose of monitoring the convergence of turbulent kinetic energy. To do this, the computation was run until centerline velocities were converged. An axial line was drawn at the radial location of the maximum turbulent kinetic energy. This line was called the equivalent lip line. Changes in the value of turbulent kinetic energy along the equivalent lip line were monitored. A "final solution based on turbulent kinetic energy" was reached when changes in turbulent kinetic energy along this line were below 0.01 percent. This criteria was applied to axial locations greater than five fan diameters downstream of the fan nozzle exit plane to the end of the domain.

\section{$\underline{\text { Results }}$}

Comparisons between the observed and calculated jet plume begin with the flooded contour plots in Figures 4 through 7. Comparisons are made of the axial velocity distributions, total temperature and total pressure distributions, and the distribution of turbulent kinetic energy. Black vertical lines are visible on each plot which indicate the four axial stations where the line plots shown in Figures 8 through 11 are located $(\mathrm{X} / \mathrm{D}=1.08,3.09,6.39$, and 8.04). All lengths are nondimensionalized by the fan diameter. Qualitatively, the three Navier-Stokes codes appear to predict the 
magnitude and distributions of axial velocity, total temperature, and total pressure reasonably well.

The agreement between the experimental distribution of turbulent kinetic energy and the values calculated by each of the three Navier-Stokes codes is not as close. There is a mismatch between the location and magnitude of the area of maximum turbulent kinetic energy. The codes predict that the area of maximum turbulent kinetic energy occurs farther downstream that what was seen in the experiment. The CRAFT code predicted a value of the maximum turbulent kinetic energy approximately $20 \%$ lower than the measured value, with the location of the maximum approximately $22 \%$ farther downstream. NPARC underpredicted the maximum turbulent kinetic energy by approximately $30 \%$, with the maximum located nearly $25 \%$ farther downstream. WIND came closer to predicting the measured maximum turbulent kinetic energy by underpredicting by only $14 \%$, but the location of this maximum was farther downstream than the other two codes at approximately $41 \%$ farther than the data.

The reason for this discrepancy is not entirely clear. It is possible that the difference in the turbulent kinetic energy plots are a result of the way that the data has been averaged and the way that the codes calculate turbulent kinetic energy. The flow solvers all use Favre-averaged variables, calculating turbulence kinetic energy as variance of momentum fluctuations divided by the average density, whereas the experimental turbulence kinetic energy is directly calculated by variance of velocity. The unknown correlation of density and velocity fluctuations make these two measures somewhat incompatible. Alternately, it is also possible that the more intense mixing seen in the experimental data is a result of three-dimensional effects not even modeled in the 2-D axisymmetric calculations.

Taking the investigation further, efforts were made to determine if and where this two-stream jet exhibited single-stream round jet behavior. The data and computational results were examined, and the non-dimensionalized velocity profiles were plotted. The experiment showed that the axial velocity profiles were self-similar at axial locations greater than approximately six fan diameters downstream of the fan nozzle exit plane. Self-similarity of the computed nondimensionalized axial velocities were seen at axial locations greater than ten fan diameters downstream of the fan nozzle exit plane. The non-dimensional velocity profiles in the regions of self-similarity are shown in Figure 12. According to References 4 through 6, the spreading rate of the jet in this region should be constant. Figure 13 shows that the calculated spreading rate as a function of non-dimensionalized axial distance.
Demonstrating that there was a region of self-similarity was interesting for several reasons. Firstly, it relates this more complicated geometry to the better understood round free jet case which may provide more consistent interpretations of results. Secondly, since the spreading rate in this region is a single constant number which represents the way in which the jet mixes (which is of particular importance if acoustic predictions are to be made) it lends itself well to be used as a metric in a grid study.

A grid study was conducted using the WIND code. Following the procedures described by Roache in Reference 6, two additional grids were made, containing approximately ten and twenty percent more grid points in each direction than the original grid, while keeping all other packing and distribution features the same. Grid 1 was the original grid and had dimensions of 547 by 160 . Grid 2 had dimensions of 603 by 177, and the finest mesh, Grid 3, had dimensions of 658 by 192 . The self-similar velocity profiles for these two finer meshes are also found in Figure 12. The spreading rate was calculated for each of the three meshes, and Richardson extrapolation was used to estimate the asymptotic value of the spreading rate. The spreading rates were plotted in Figure 14 as a function of non-dimensionalized grid spacing. Grid spacing was non-dimensionalized by the spacing of the finest grid. It was found that the asymptotic value of the spreading rate was 0.004652 with an error band of 0.3676 percent. Results from the MGBK code which will be discussed below, show that these computational meshes did yield grid independent acoustic results.

\section{$\underline{\text { Acoustic Predictions }}$}

\section{Computational Details}

Turbulent mixing noise from the underlying unsteady flow is predicted using averaged equations of motion. This involves two steps: modeling of noise sources of fine-scale turbulence, and mean-flow refraction effects as the sound propagates through the shear flow to a far-field observer. The governing equation describing the source as well as refraction effects is the third-order wave equation known as Lilley's equation. For our application, this equation is linearized about a unidirectional transversely sheared mean flow. The relevant noise sources are the so-called self- and shear-noise terms as described in MGBK prediction methodology. ${ }^{8}$ The remaining sources are neglected as argued in Reference 9. As usual, a highfrequency Green's function derived for a locally parallel jet ${ }^{10}$ is used to account for propagation effects. This function is essentially responsible for attenuation of the high-frequency noise near the zone of silence. It is also responsible for the peak directivity that is formed near the zone of relative silence. 
Two-point space-time correlation of turbulent velocity components is modeled as an axisymmetric tensor about the direction of mean flow. This model ${ }^{8}$ introduces two additional parameters, i.e., $u_{2}^{2} / u_{1}^{2}$ and $\Delta=L_{2} / L_{1}$ which need to be provided as input to noise prediction. These factors define the ratio of the axial and transverse velocity components and length-scales. Subcripts 1 and 2 denote the axial and lateral directions respectively. In the special case of an isotropic turbulence both parameters become unity. In general, sound spectral intensity is scaled as $k^{7 / 2}\left(\Omega \tau_{o}\right)^{4}$, where the characteristic frequency $\tau_{o}^{-1}$ is related to turbulence kinetic energy $k$ and its dissipation rate $\varepsilon$ as $\tau_{o}=2 k / \varepsilon$ and $\Omega$ is source frequency.

\section{$\underline{\text { Results }}$}

Noise spectra and directivity are presented for three sets of RANS predictions, i.e., NPARC, CRAFT and WIND on an $\operatorname{arc} R / D=62.5$. Comparison of the turbulence profiles indicates that CRAFT and WIND solutions predict a higher level of turbulent kinetic energy at the peak compared to the NPARC solution, e.g., by as much as $20 \%$ at $X / D=8.04$. The predicted noise levels (Fig. 15) also differ between 2.0 to $3.0 \mathrm{~dB}$ as indicated by $k^{7 / 2}$ scaling law. This difference in predicted noise is primarily reflected into the low- to mid-range frequency. High-frequency noise is mostly radiated near the exit and predictions exhibit better agreement in this range as there is less discrepancy in predicted turbulence level near the exit. The sound pressure level directivity (Fig. 16) shows reasonable agreement with data at most angles. Near the peak, however, the agreement is not as good. It is not clear if this difference is due to contribution from other sources, such as larger scale of motion that radiate at shallow angles, or selection of turbulence anisotropy parameters $\left(\Delta, u_{2}^{2} / u_{1}^{2}\right)$ or perhaps the Green's function itself. Here, we have selected $(0.6,0.6)$ as our input parameters. For example, Figure 17, obtained with the NPARC solution, shows how Delta-dB in noise level from $90^{\circ}$ to $160^{\circ}$ depends on selection of anisotropy factors. The figure shows that a new set of parameters such as $\left(\Delta, u_{2}^{2} / u_{1}^{2}\right)=(0.73,0.5)$ could change Delta$\mathrm{dB}$ in noise directivity from its current value of 13.0 to $16.0 \mathrm{~dB}$. In general, increased anisotropy adds to the noise level at near peak angles.

The effect of grid density on radiated noise is studied by considering two WIND solutions, i.e., Grid 1 (547 by 160) which was discussed above, and the finest grid-Grid 3 (658 by 192). The predicted spectra are virtually indistinguishable, as the maximum difference in noise level is of the order of $0.10 \mathrm{~dB}$. Comparison of two RANS solutions further confirms lack of sensitivity of the mean and turbulence parameters to grid density beyond Grid 1. Figure 18 shows mean velocity, turbulence kinetic energy and characteristic frequency comparisons at $X / D=7.5$.

\section{Conclusions}

Conclusions can be drawn from the results presented here that three Navier-Stokes solversCRAFT's code, WIND, and NPARC — are all capable of providing mean flow predictions suitable for input into the MGBK noise prediction code. Comparable results were achieved from all three codes using the same grid and input conditions. All three codes underpredicted the maximum value of turbulent kinetic energy and calculated that the area of maximum turbulent kinetic energy would occur farther downstream than the experiment showed. The differences between the predicted turbulent kinetic energy distributions exhibited a 2.0 to $3.0 \mathrm{~dB}$ difference in calculated noise levels, as indicated by $k^{7 / 2}$ scaling law.

Since the mean flow results were be used as input for the MGBK acoustic prediction code, convergence criteria for this problem were discussed. It is recommended that a final solution would have to meet three criteria: the L2 residual error must have dropped at least three orders of magnitude, and that changes in both the centerline axial velocities and turbulent kinetic energy along an equivalent lip line be below 0.01 percent over a 5000 iteration set.

Finally, results from the grid study using WIND and MGBK showed that the original computational mesh yielded grid independent acoustic results. Spreading rate can be calculated and is a useful metric for a grid study.

\section{$\underline{\text { References }}$}

1. Kenzakowski, D.C., Shipman, J., Dash, S.M., Bridges, J., and Saiyed, N., "Study of Two-stream Laboratory Jets with Passive Mixing Enhancements for Noise Reduction," AIAA-2000-0219.

2. Georgiadis, N.J., Yoder, D.A., and DeBonis, J.R. "A Comparison of Three Navier-Stokes Solvers for Exhaust Nozzle Flowfields," NASA/TM-1999209184.

3. Hamed, A., Khavaran, A., and Lee, S., "The Flow and Acoustic Predictions for a High By-Pass Ratio Exhaust Nozzle," AIAA-98-3257.

4. Abramovich, G.N., "The Theory of Turbulent Jets," MIT Press, 1963.

5. Hinze, J.O., "Turbulence," McGraw-Hill, 1974.

6. Wilcox, D.C., "Turbulence Modeling for CFD," DCW Industries, 2000. 
7. Roache, P.J., "Verification and Validation in Computational Science and Engineering," Hermosa Publications, 1998.

8. Khavaran, A., "Role of Anisotropy in Turbulent Mixing Noise," AIAA Journal, Vol. 37(7), 1999.

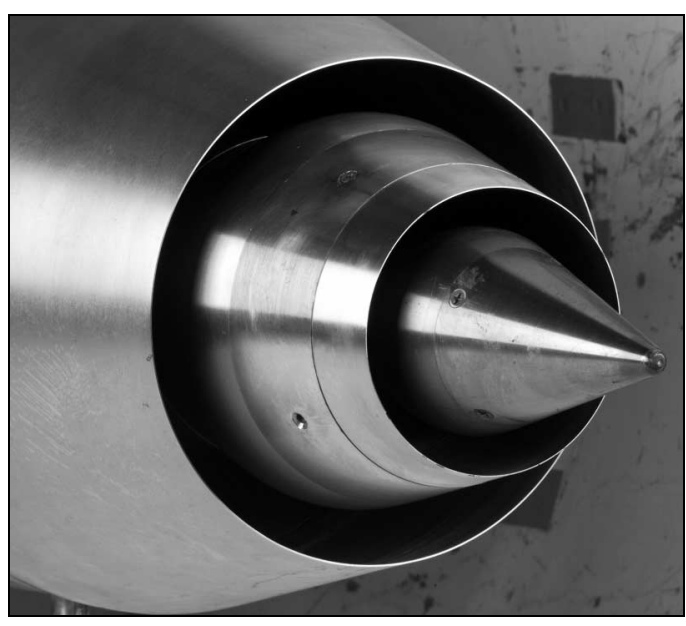

Figure 1: Baseline Nozzle, 3BB
9. Colunius, T., Lele, S.K., and Moin, P., "Sound Generation in a Mixing Layer," J. Fluid Mechanics, Vol. 330, 1977.

10. Balsa, T.F., "The Far Field of High Frequency Convected Singularities in Sheared Flows with Application to Jet Noise Prediction," J. Fluid Mechanics, Vol. 74, 1976.

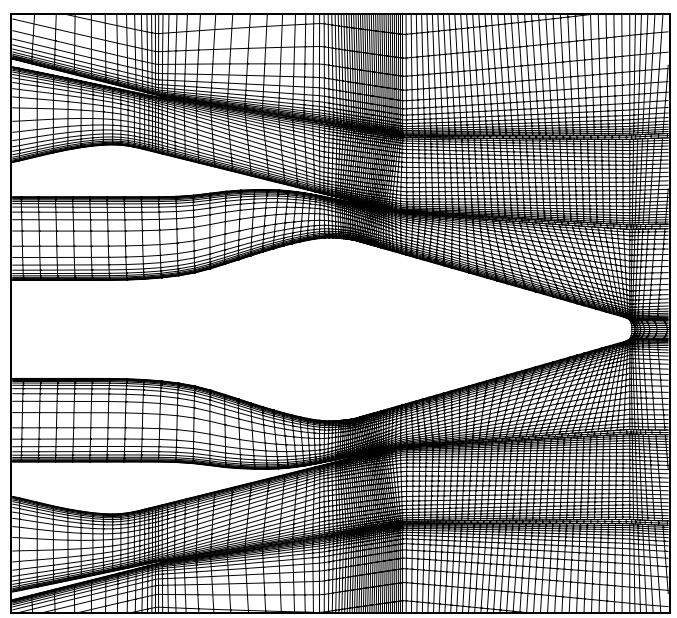

Figure 2: Close-up of computational mesh

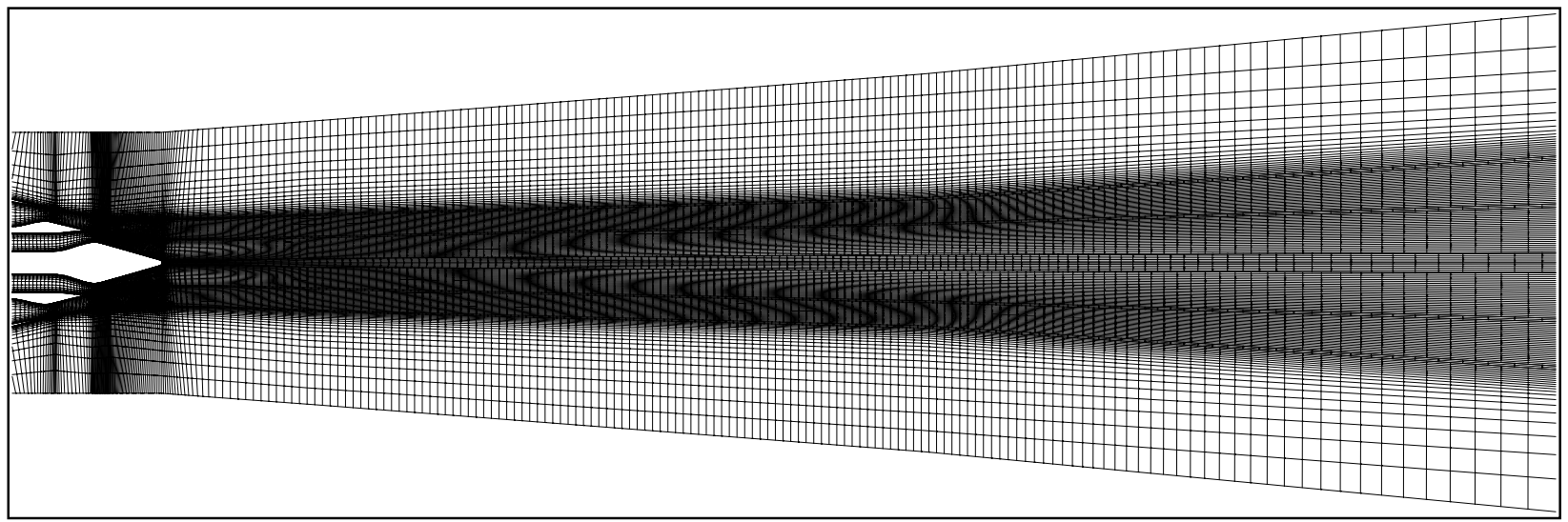

Figure 3: Computational mesh 


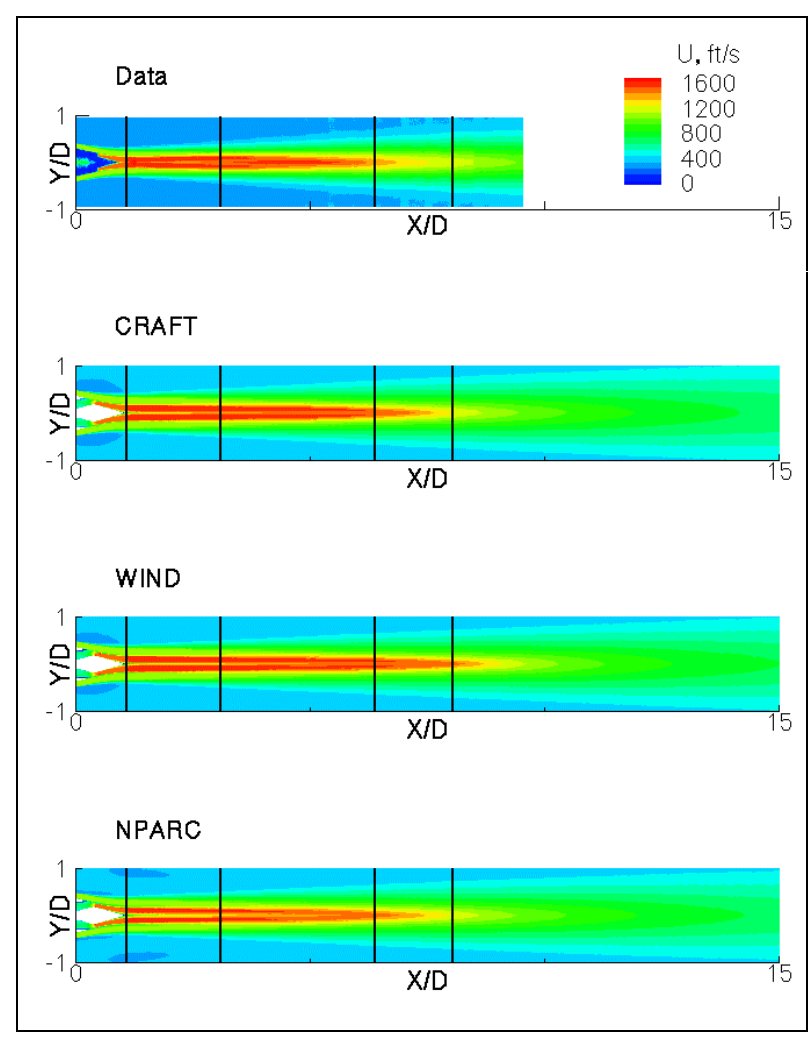

Figure 4: Axial Velocity Distributions

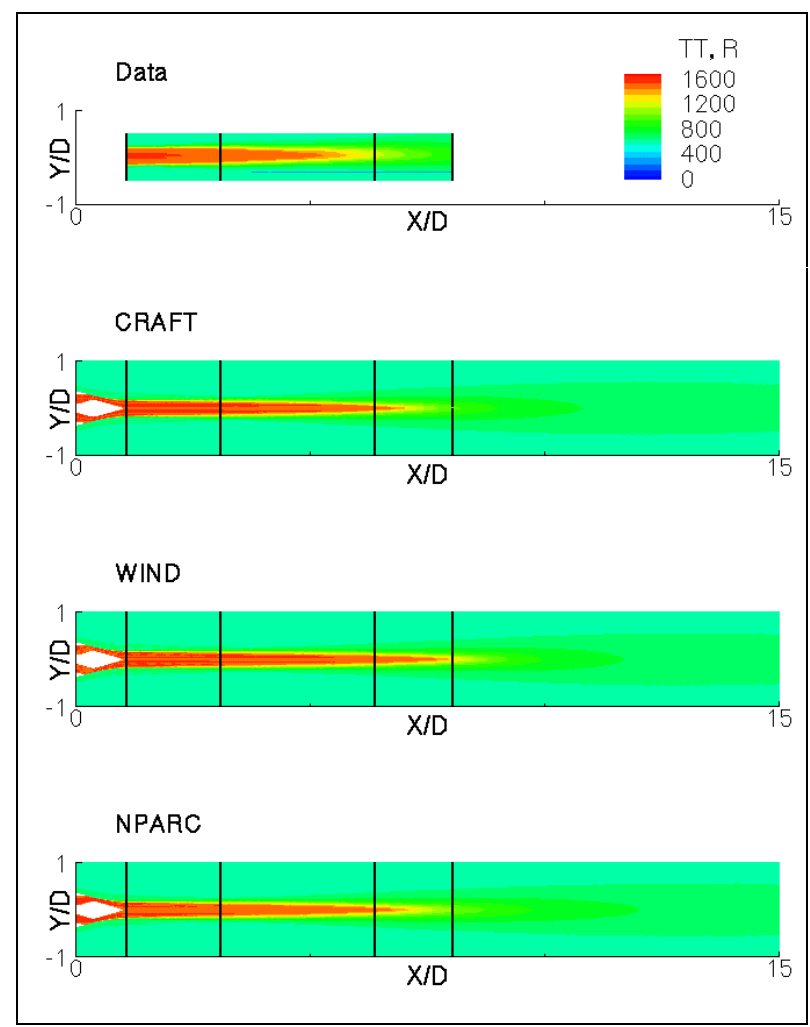

Figure 6: Total Temperature Distributions

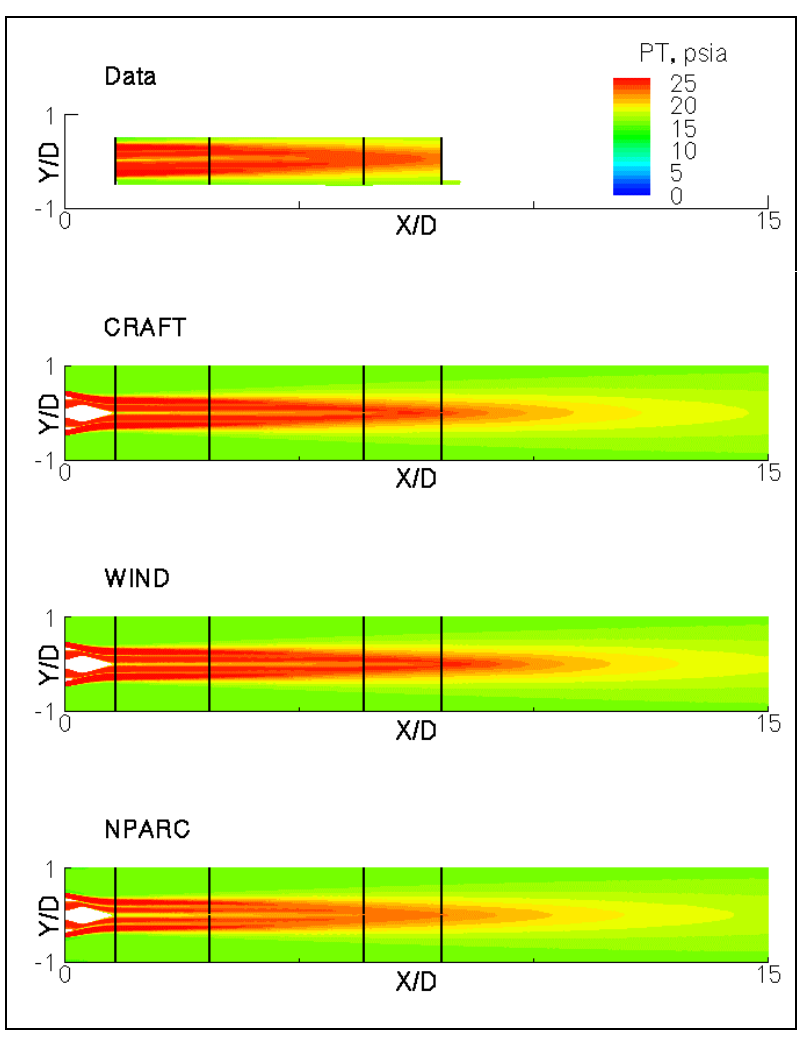

Figure 5: Total Pressure Distributions

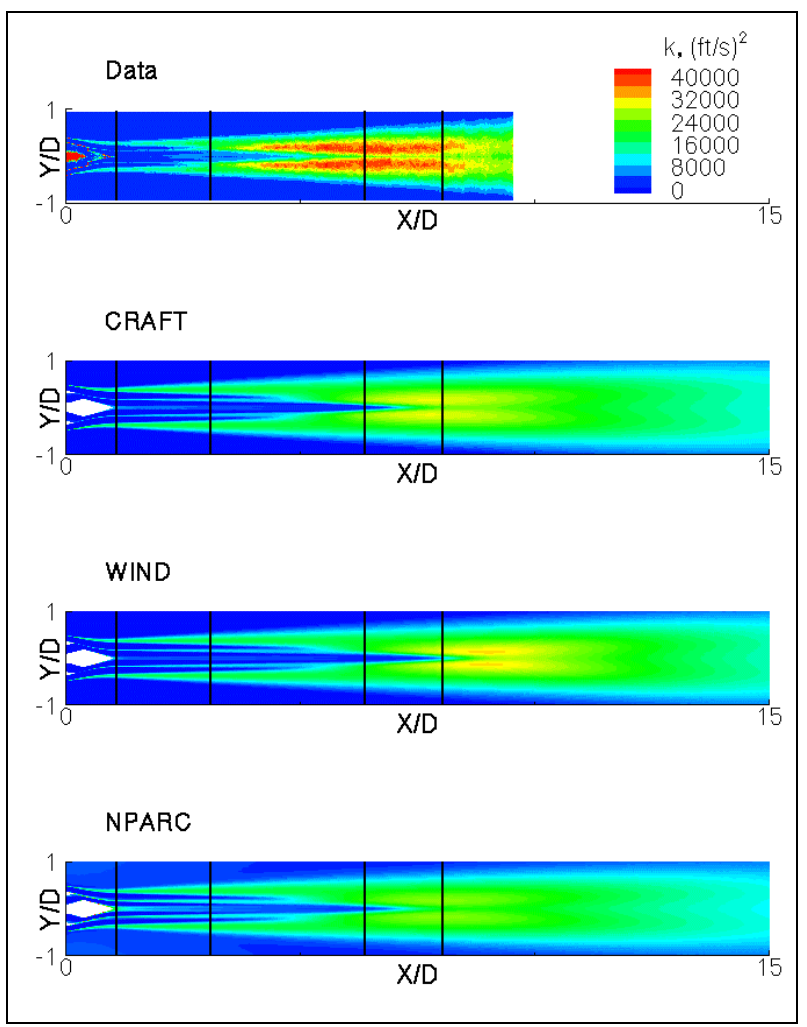

Figure 7: Turbulent Kinetic Energy Distributions 

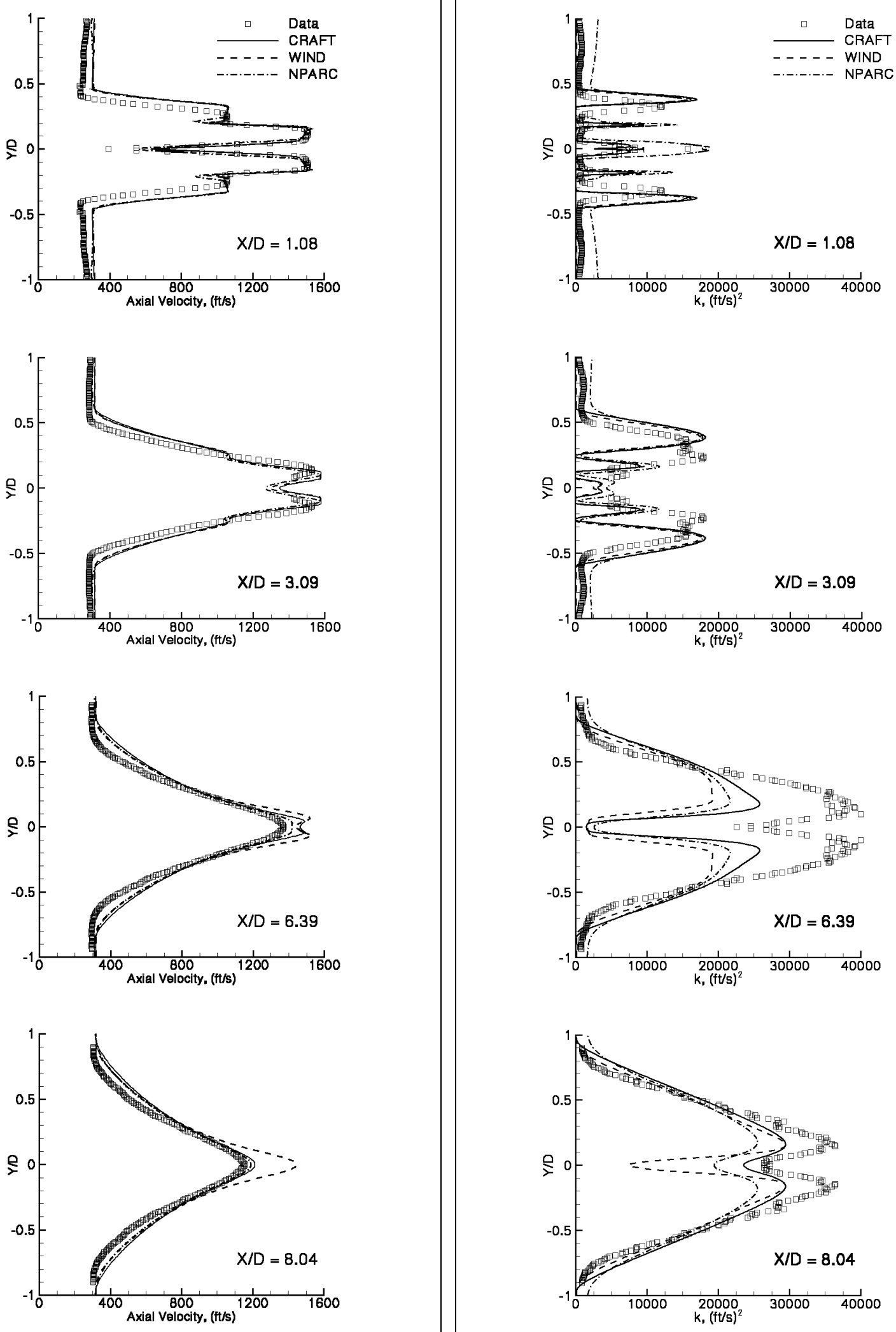

Figure 8: Axial Velocity Distributions

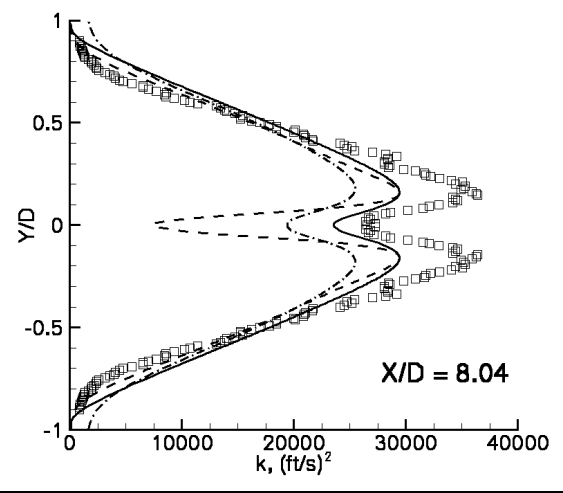

Figure 9: Turbulent Kinetic Energy 

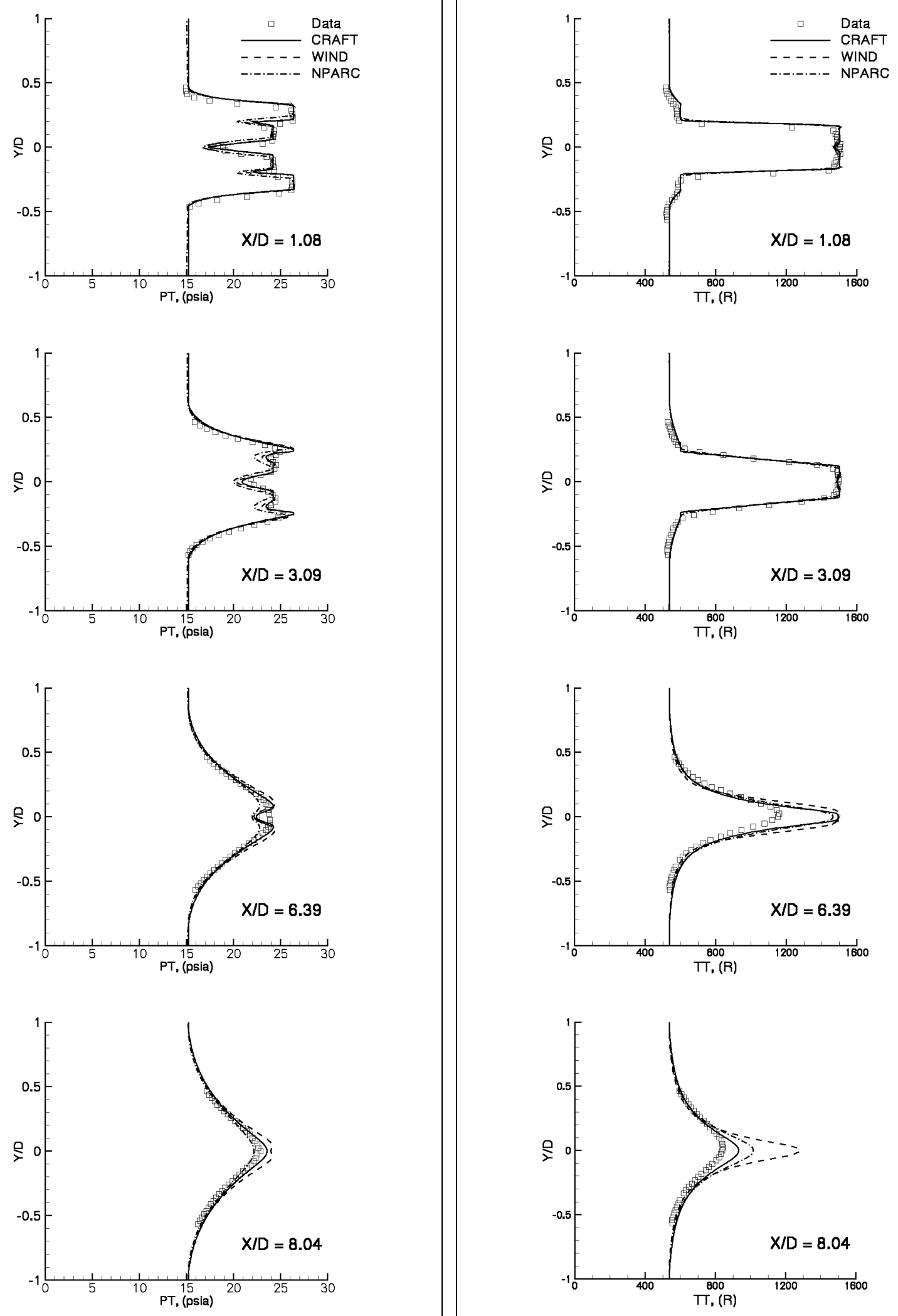

Figure 10: Total Pressure Distributions

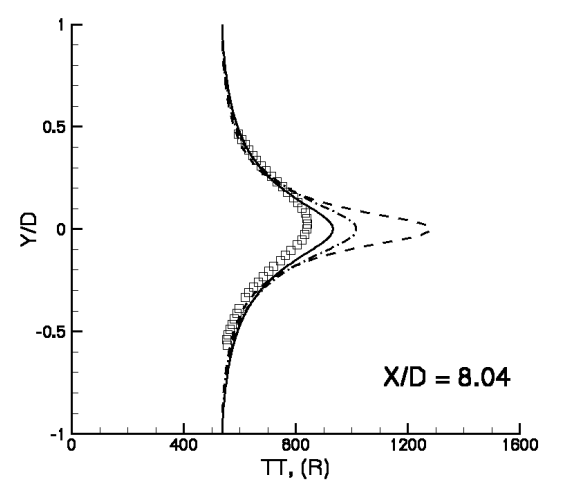

Figure 11: Total Temperature Distributions 


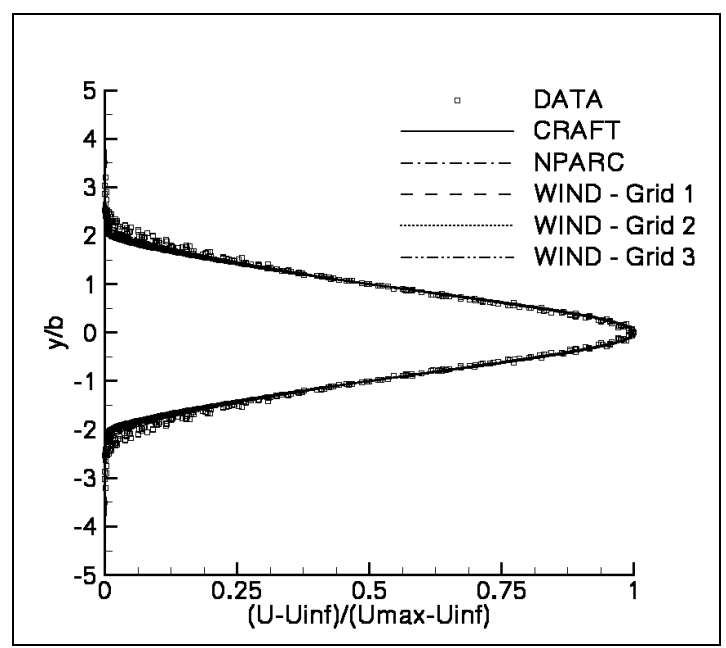

Figure 12: Self-Similar Velocity Profiles

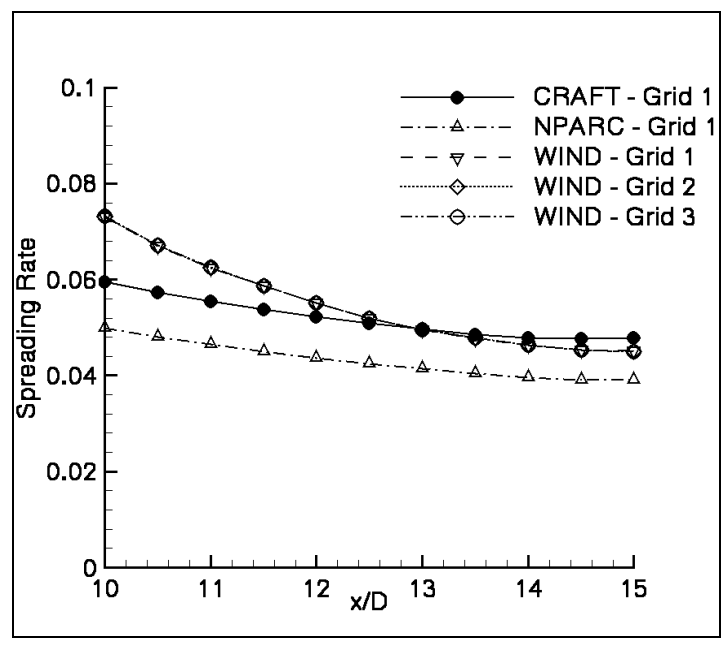

Figure 13: Spreading Rate vs. Axial Distance

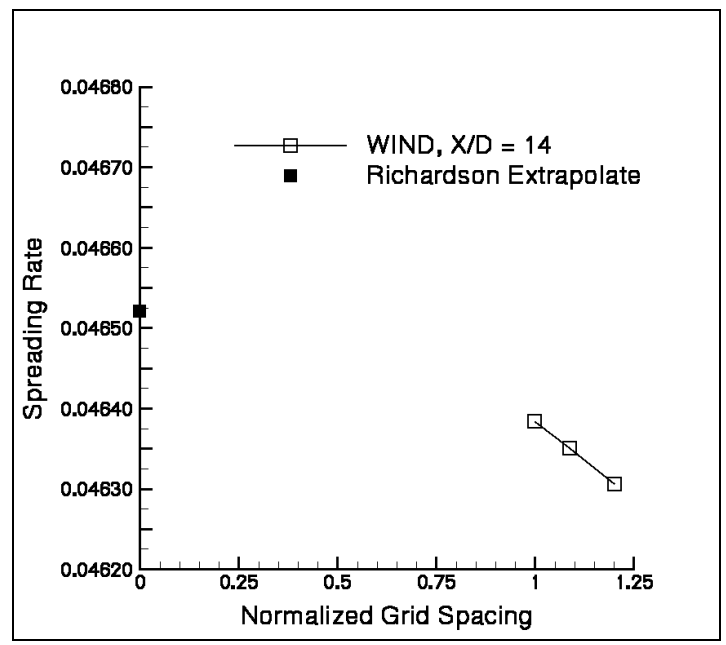

Figure 14: WIND Grid Study Results

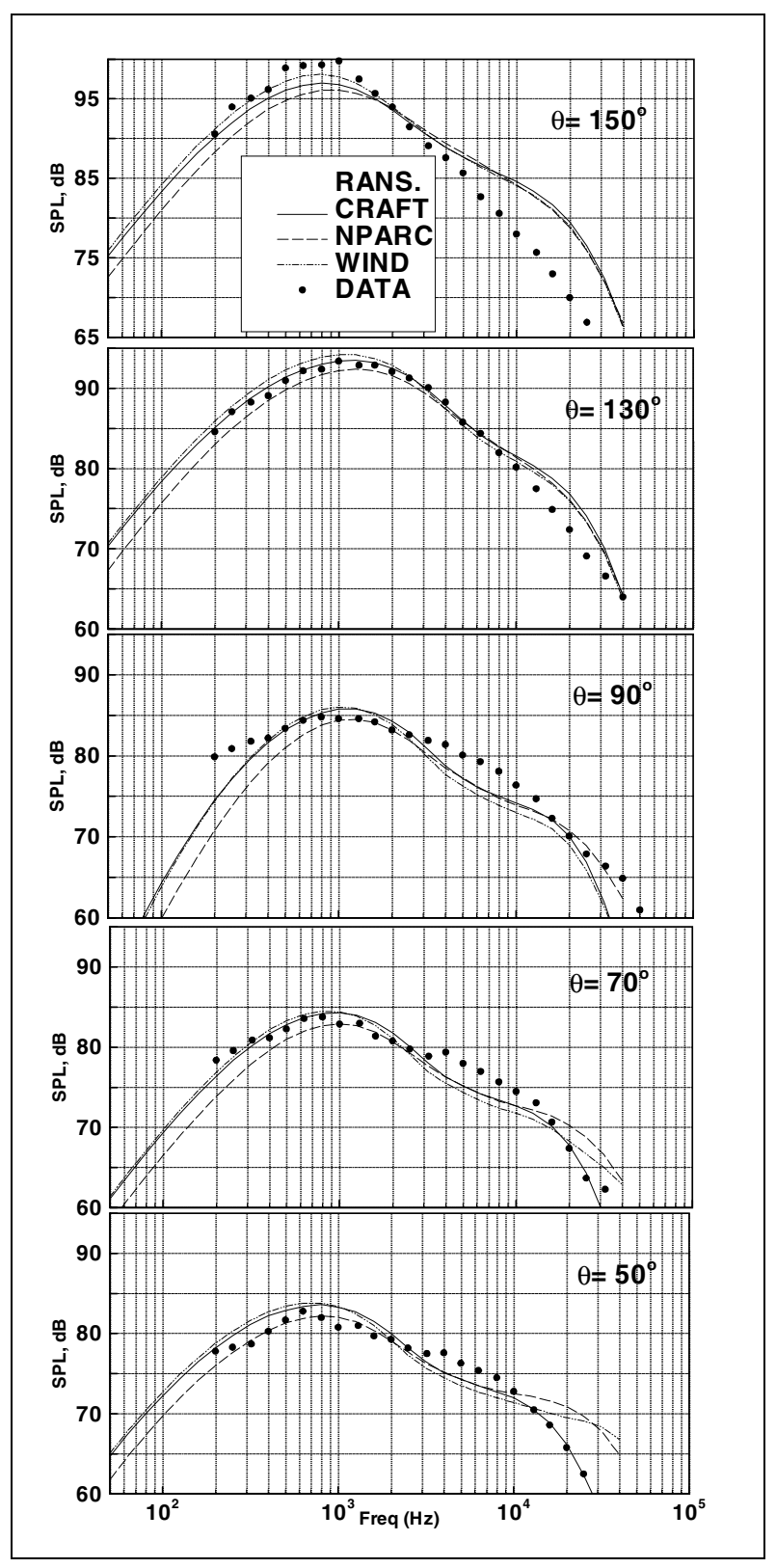

Figure 15: Predicted Noise Spectra at Indicated Inlet Angles. 


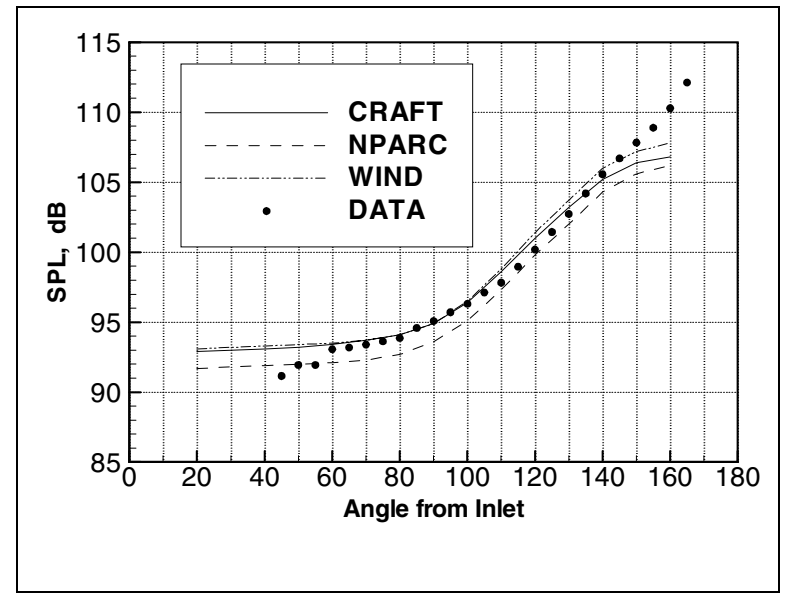

Figure 16: Sound Pressure Level Directivity

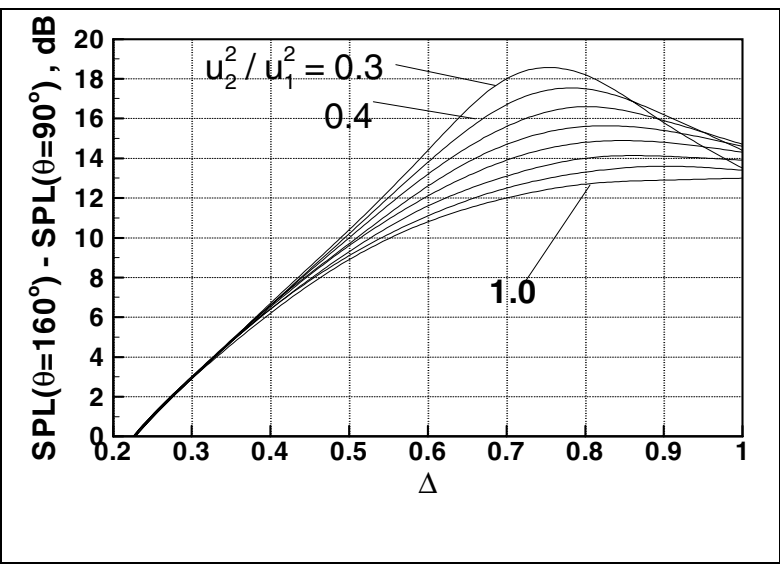

Figure 17: Delta-dB in Noise level from $90^{\circ}$ to $160^{\circ}$ vs. Length-Scale ratio $\Delta$ and Turbulence ratio $u_{2}^{2} / u_{1}^{2}$.
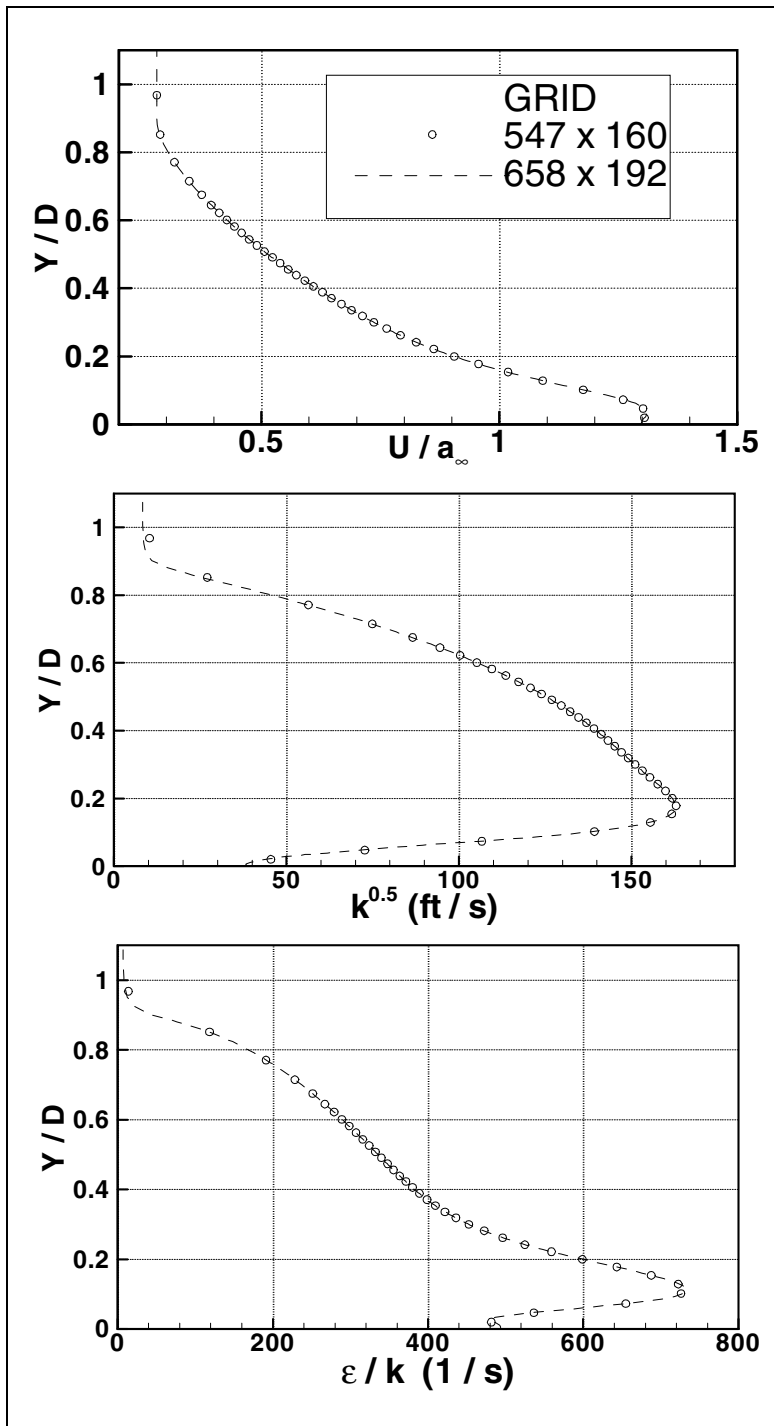

Figure 18: Effect of Grid Density on RANS Predictions (WIND) at $X / D=7.5$. 
Public reporting burden for this collection of information is estimated to average 1 hour per response, including the time for reviewing instructions, searching existing data sources, gathering and maintaining the data needed, and completing and reviewing the collection of information. Send comments regarding this burden estimate or any other aspect of this collection of information, including suggestions for reducing this burden, to Washington Headquarters Services, Directorate for Information Operations and Reports, 1215 Jefferson Davis Highway, Suite 1204, Arlington, VA 22202-4302, and to the Office of Management and Budget, Paperwork Reduction Project (0704-0188), Washington, DC 20503.

\begin{tabular}{|l|l|l}
\hline 1. AGENCY USE ONLY (Leave blank) & $\begin{array}{c}\text { 2. REPORT DATE } \\
\text { February } 2002\end{array}$ & $\begin{array}{c}\text { 3. REPORT TYPE AND DATES COVERED } \\
\text { Technical Memorandum }\end{array}$ \\
\hline
\end{tabular}

\section{TITLE AND SUBTITLE}

5. FUNDING NUMBERS

Flowfield Comparisons From Three Navier-Stokes Solvers for an Axisymmetric Separate Flow Jet

6. AUTHOR(S)

WU-781-30-12-00

L. Danielle Koch, James Bridges, and Abbas Khavaran

7. PERFORMING ORGANIZATION NAME(S) AND ADDRESS(ES)

National Aeronautics and Space Administration

John H. Glenn Research Center at Lewis Field

Cleveland, Ohio 44135-3191

8. PERFORMING ORGANIZATION

REPORT NUMBER

E-13167

\section{SPONSORING/MONITORING AGENCY NAME(S) AND ADDRESS(ES)}

National Aeronautics and Space Administration

Washington, DC 20546-0001

10. SPONSORING/MONITORING AGENCY REPORT NUMBER

NASA TM-2002-211350

AIAA-2002-0672

\section{SUPPLEMENTARY NOTES}

Prepared for the 40th Aerospace Sciences Meeting and Exhibit sponsored by the American Institute of Aeronautics and Astronautics, Reno, Nevada, January 14-17, 2002. L. Danielle Koch and James Bridges, NASA Glenn Research Center; Abbas Khavaran, QSS Group, Inc., Cleveland, Ohio 44135. Responsible person, L. Danielle Koch, organization code 5940, 216-433-5656.

12a. DISTRIBUTION/AVAILABILITY STATEMENT 12b. DISTRIBUTION CODE

Unclassified - Unlimited

Subject Categories: 02, 34, and 71

Distribution: Nonstandard

Available electronically at http://gltrs.grc.nasa.gov/GLTRS

This publication is available from the NASA Center for AeroSpace Information, 301-621-0390.

13. ABSTRACT (Maximum 200 words)

To meet new noise reduction goals, many concepts to enhance mixing in the exhaust jets of turbofan engines are being studied. Accurate steady state flowfield predictions from state-of-the-art computational fluid dynamics (CFD) solvers are needed as input to the latest noise prediction codes. The main intent of this paper was to ascertain that similar Navier-Stokes solvers run at different sites would yield comparable results for an axisymmetric two-stream nozzle case. Predictions from the WIND and the NPARC codes are compared to previously reported experimental data and results from the CRAFT Navier-Stokes solver. Similar k-epsilon turbulence models were employed in each solver, and identical computational grids were used. Agreement between experimental data and predictions from each code was generally good for mean values. All three codes underpredict the maximum value of turbulent kinetic energy. The predicted locations of the maximum turbulent kinetic energy were farther downstream than seen in the data. A grid study was conducted using the WIND code, and comments about convergence criteria and grid requirements for CFD solutions to be used as input for noise prediction computations are given. Additionally, noise predictions from the MGBK code, using the CFD results from the CRAFT code, NPARC, and WIND as input are compared to data.

14. SUBJECT TERMS

Navier-Stokes; Exhaust nozzle; Mixing; Turbulence; Aerodynamic noise 15. NUMBER OF PAGES 16 16. PRICE CODE

\begin{tabular}{|c|c|c|}
\hline $\begin{array}{c}\text { 17. SECURITY CLASSIFICATION } \\
\text { OF REPORT } \\
\text { Unclassified }\end{array}$ & $\begin{array}{c}\text { 18. SECURITY CLASSIFICATION } \\
\text { OF THIS PAGE } \\
\text { Unclassified }\end{array}$ & $\begin{array}{c}\text { 19. SECURITY CLASSIFICATION } \\
\text { OF ABSTRACT } \\
\text { Unclassified }\end{array}$ \\
\hline
\end{tabular}

NSN 7540-01-280-5500

Standard Form 298 (Rev. 2-89) 

